\title{
The influence of a high power diode laser (HPDL) generated glaze on the wetting characteristics and the subsequent HPDL enamelling of ordinary Portland cement
}

\author{
J. Lawrence and L. Li.
}

Manufacturing Division, Department of Mechanical Engineering, University of Manchester Institute of Science and Technology (UMIST), Manchester, M60 1QD, UK.

\section{Correspondence}

Dr. Jonathan Lawrence

Manufacturing Division,

Department of Mechanical Engineering,

University of Manchester Institute of Science and Technology (UMIST),

Manchester,

M60-1QD,

UK.

Tel : (44) 161 236-3311 ext. 3806

Fax : (44) 161 200-3803

e-mail : j.lawrence@umist.ac.uk 


\begin{abstract}
High power diode laser (HPDL) surface glazing of the ordinary Portland cement (OPC) surface of concrete was found to effect significant changes in the wettability characteristics of the OPC. This behaviour was identified as being primarily due to: (i) the polar component of the OPC surface energy increasing after HPDL glazing from 3.46 to $15.56 \mathrm{mJm}^{-2}$, (ii) the surface roughness of the OPC decreasing from an Ra value of 21.91 to $2.88 \mu \mathrm{m}$ after HPDL glazing and (iii) the relative surface $\mathrm{O}_{2}$ content of the OPC increasing by $4.5 \mathrm{at} \%$ after HPDL glazing. HPDL glazing was consequently identified as occasioning a decrease in the enamel contact angle from an initial value of $109^{0}$ to $31^{0}$, thus allowing the vitreous enamel to wet the OPC surface.
\end{abstract}

Keywords: High power diode laser (HPDL); Ordinary Portland cement (OPC); Enamel; Glazing; Wettability; Surface energy 


\section{Introduction}

The unique characteristics of lasers provides them with the capability for the non-contact processing of materials which are otherwise difficult to process. Concrete is one such material since it is a composite, consisting of an array of fine and coarse aggregate pieces embedded within an ordinary Portland cement (OPC) matrix. Consequently the processing and surface treatment of concrete can be a difficult undertaking. This present work describes the use of high power diode laser (HPDL) radiation to enhance the wettability characteristics of the 'as-cast' OPC surface of concrete and the effects thereof on the characteristics of a subsequently HPDL fired enamel glaze. The value of such an investigation would be to elucidate the reasons behind the successful generation of a durable and long-lasting surface seal on the OPC surface of the concrete, which has been shown by Lawrence and Li to be viable means of extending the life and applications base of the concrete [1]. It is a distinct possibility that such developments may yield significant economic benefits.

The laser processing of concrete is a field of ongoing research, with many studies having been carried out to investigate the technique itself and the associated phenomena. Most of the research, however, has concentrated on the laser cutting of concrete and reinforced concrete using high power $\mathrm{CO}_{2}$ lasers, most prominently with regard to nuclear reactor decommissioning [2-4]. Also, as part of nuclear plant decommissioning, Li et al. [5-8] conducted research to determine the workability of several laser techniques for sealing/fixing radioactive contamination onto concrete surfaces. Such techniques experimented with were: direct glazing of the concrete, single and multiple layer fusion cladding and combined chemical/fusion cladding. Work by Sugimoto et al. [9] focused upon modifying the surface appearance and surface properties of cement based materials using a high power $\mathrm{CO}_{2}$ laser. The laser treatment produced novel surfaces, with surface textures, properties and appearance unique to laser treatment. The resultant physical characteristics and mechanical behaviour of the post-process cement based materials was later fully characterised by Wignarajah et al. [10]. Borodina et al. [11] has carried out investigations into the structural changes within the composition of zirconia concrete caused by surface exposure to $\mathrm{CO}_{2}$ laser radiation, detailing microstructural changes, phase changes and the absorptivity characteristics. In all of these studies, spallation and excessive cracking and porosity formation were found to be major problems undermining the performance of the laser treated surface layer. However, Lawrence and Li [12-15] have treated the OPC surface of concrete with both $\mathrm{CO}_{2}$ and HPDLs. The HPDL generated OPC glaze was shown to 
be more than an effective surface modification insofar as it provided superior mechanical, physical and chemical characteristics over an untreated or $\mathrm{CO}_{2}$ laser treated OPC surface.

To date, very little published work exists pertaining to the use of lasers for altering the surface properties of materials in order to improve their wettability characteristics. Notwithstanding this, it is recognised within the currently published work that laser irradiation of a metal surface can bring about changes in the metal's wettability characteristics. Previously Zhou et al. [16, 17] carried out work on the laser coating of aluminium alloys with ceramic materials $\left(\mathrm{SiO}_{2}, \mathrm{Al}_{2} \mathrm{O}_{3}\right.$, etc. $)$, reporting on the well documented fact that generated oxide layers often promote metal/oxide wetting. Further, Heitz et al. [18], Henari et al. [19] and Olfert et al. [20] have found that excimer laser treatment of metals results in improved coating adhesion. The improvements in adhesion were attributed to the fact that the excimer laser treatment resulted in a smoother surface and as such enhanced the action of wetting. Yet the reasons for these changes with regard to changes in the material's surface morphology, surface composition and surface energy are not reported. However, in a number of more comprehensive investigations by Lawrence et al., which compared the effects of $\mathrm{CO}_{2}, \mathrm{Nd}: \mathrm{YAG}$, excimer and HPDL radiation on the wettability characteristics of a mild steel $[21,22]$ and a $\mathrm{SiO}_{2} / \mathrm{Al}_{2} \mathrm{O}_{3}$-based ceramic material [23] it was found that changes in the wettability characteristics of the steel varied depending upon the laser type. Furthermore, Lawrence et al. have conducted numerous studies to investigate the feasibility and characteristics of laser enamelling ceramic materials [24-27] and steels [28, 29].

\section{Theoretical background}

\subsection{Contact angle and wettability}

When a drop of liquid is placed on a solid surface it may remain as a spherical drop, or spread to cover (wet) the solid surface [30]. The angle with which the liquid subtends the solid is known as the contact angle. In practice, for wetting to occur the contact angle is less than $90^{\circ}$. If the contact angle is greater than $90^{\circ}$ then the liquid does not wet the solid and no adhesion occurs [30]. Once irradiated by the HPDL beam the enamel powder melts, transforming to a liquid phase. As such, the process of the bonding of the enamel to the HPDL treated OPC substrate is determined by the wettability of the two component parts. When a drop of liquid is brought into contact with a flat solid surface, the final shape taken by the drop, and thus whether it will wet the surface or not, depends upon the relative 
magnitudes of the molecular forces that exist within the liquid (cohesive) and between the liquid and the solid (adhesive) [30]. The index of this effect is the contact angle, $\theta$, which the liquid subtends with the solid. $\theta$ is related to the solid and liquid surface energies, $\gamma_{\mathrm{sv}}$ and $\gamma_{\mathrm{lv}}$, and the solid-liquid interfacial energy $\gamma_{\mathrm{sl}}$, through the principle of virtual work expressed by the rearranged Young's equation:

$$
\cos \theta=\frac{\gamma_{s v}-\gamma_{s l}}{\gamma_{l v}}
$$

Clearly, to achieve wetting $\gamma_{\mathrm{sv}}$ should be large, while $\gamma_{\mathrm{sl}}$ and $\gamma_{\mathrm{lv}}$ should be small. Hence liquids of a lower surface tension will always spread over a solid surface of higher surface tension in order to reduce the total free-energy of the system [31]. This is due to fact that the molecular adhesion between solid and liquid is greater than the cohesion between the molecules of the liquid [30].

The adhesion energy of a liquid to a solid surface (the work of adhesion) $W_{a d}$, is given by the YoungDupre equation:

$$
W_{a d}=\gamma_{l v}(1+\cos \theta)
$$

It is important to consider also the influence of the substrate surface roughness on the wetting contact angle. Rough grooves on a surface, which may contribute to the influence of contact angles, can be categorised as either radial or circular grooves. Any practical rough surface can be represented by a combination of these two cases [32]. In fact two roughness parameters can be defined: the Wenzel type, $D_{R}[33]$ and the Cassie/Baxter type, $F_{R}$ [34]. In the case that wetting spreads radially, as is the likely case with the OPC surface of concrete, then the resulting radial contact angle, $\theta_{\text {rad, }}$ is related to the theoretical contact angle, $\theta_{t h}$, by

$$
\cos \theta_{\text {rad }}=D_{R}\left(1-F_{R}\right) \cos \theta_{t h}-F_{R}
$$

According to Neumann [35], only if $F_{R}$ is equal to zero, then a model similar to that for heterogeneous solid surfaces can be developed in order to account for surface irregularities, being given by Wenzel's equation:

$$
r\left(\gamma_{s v}-\gamma_{s l}\right)=\gamma_{l v} \cos \theta_{w}
$$


where $r$ is the roughness factor defined as the ratio of the real and apparent surface areas and $\theta_{w}$ is the contact angle for the wetting of a rough surface. It is important to note that Wenzel's treatment is only effective at the position of wetting triple line [32]. Nevertheless, it is clear from Eq. (4) that the influence of surface roughness on the contact angle is to cause an increase in the contact angle. Thus, the smoother the contact surface is, then the smaller the contact angle will be.

\subsection{Surface energy and the polar/dispersive characteristics}

The intermolecular attraction which is responsible for surface energy, $\gamma$, results from a variety of intermolecular forces whose contribution to the total surface energy is additive [36]. The majority of these forces are functions of the particular chemical nature of a certain material, and as such the total surface energy comprises of $\gamma^{\mathrm{p}}$ (polar or non-dispersive interaction) and $\gamma^{\mathrm{d}}$ (dispersive component; since van der Waals forces are present in all systems regardless of their chemical nature). Therefore, the surface energy of any system can be described by [36]

$$
\gamma=\gamma^{d}+\gamma^{p}
$$

Similarly, $W_{a d}$ can be expressed as the sum of the different intermolecular forces that act at the interface [36]:

$$
W_{a d}=W_{a d}^{d}+W_{a d}^{p}=2\left(\gamma_{s v}^{d} \gamma_{l v}^{d}\right)^{1 / 2}+2\left(\gamma_{s v}^{p} \gamma_{l v}^{p}\right)^{1 / 2}
$$

By equating Eq. (6) with Eq. (2), the contact angle for solid-liquid systems can be related to the surface energies of the respective liquid and solid by

$$
\cos \theta=\frac{2\left(\gamma_{s v}^{d} \gamma_{l v}^{d}\right)^{1 / 2}+2\left(\gamma_{s v}^{p} \gamma_{l v}^{p}\right)^{1 / 2}}{\gamma_{l v}}-1
$$

\section{Experimental procedures}

\subsection{Materials}

The concrete studied in the experiments was the ubiquitous OPC based concrete. For the purpose of experimental convenience the as-received concrete blocks were sectioned into squares $(120 \mathrm{x} 120 \mathrm{x}$ 
$20 \mathrm{~mm}^{3}$ ) prior to HPDL treatment. The composition by volume of the concrete is as follows: $20 \mathrm{~mm}$ limestone aggregate (40\%), $10 \mathrm{~mm}$ limestone aggregate (14\%), zone M sand (28.5\%), OPC (10.5\%) and particulate fine aggregate $(7 \%)$. In order to obtain results of a practical and useful nature, the area of the concrete irradiated during the experiments was the naturally occurring 'as cast' OPC surface of concrete. In this case the OPC surface of the concrete had a thickness of $2.5 \mathrm{~mm}$. The composition by volume of the OPC is as follows: $\mathrm{CaO}(63.9 \%), \mathrm{SiO}_{2}(21.9 \%), \mathrm{Al}_{2} \mathrm{O}_{3}(5.7 \%), \mathrm{Fe}_{2} \mathrm{O}_{3}(2.8 \%), \mathrm{SO}_{3}$ (2.7\%), $\mathrm{MgO}(2.2 \%), \mathrm{K}_{2} \mathrm{O}(0.7 \%)$ and $\mathrm{Na}_{2} \mathrm{O}(0.1 \%)$.

The enamel used was a commercially available enamel frit (Ferro Group) which, in order to form a manageable paste, was mixed with $20 \mathrm{wt} \%$ white spirit. The composition of the enamel consisted mainly of the following: $\mathrm{SiO}_{2}, \mathrm{~B}_{2} \mathrm{O}_{3}, \mathrm{Na}_{2} \mathrm{O}, \mathrm{Mn}$ and small quantities of $\mathrm{Pb}, \mathrm{Ba}, \mathrm{MgO}, \mathrm{Al}_{2} \mathrm{O}_{3}$ and $\mathrm{Ni}$, whilst the powder size was less than $25 \mu$ m medium size.

\subsection{Laser processing procedure}

The laser used in the study was a surgical HPDL (Diomed, Inc.), emitting at $810 \pm 20 \mathrm{~nm}$ and operating in the continuous wave $(\mathrm{CW})$ mode with rated optical powers ranging from $0-120 \mathrm{~W}$. The HPDL beam was delivered to the work area by means of a $4 \mathrm{~m}$ long, $600 \mu \mathrm{m}$ core diameter optical fibre, the end of which was connected to a $2: 1$ focusing lens assembly mounted on the z-axis of a 3axis CNC gantry table. The concrete sample blocks and the enamel frit were irradiated using the defocused high order mode HPDL beam with a beam spot diameter of 2-5 $\mathrm{mm}$ and laser powers (measured at the workpiece using a Power Wizard power meter) of 20-100 W. The defocused HPDL beam was fired across the surfaces of the concrete samples by traversing the samples beneath the beam using the $\mathrm{x}$ - and $\mathrm{y}$-axis of the $\mathrm{CNC}$ gantry table at speeds ranging from $60-600 \mathrm{~mm} \mathrm{~min}^{-1}$. The laser optics were protected by means of a coaxially blown $\mathrm{O}_{2}$ shield gas jet a rate of $51 \mathrm{~min}^{-1}$.

\subsection{Wetting and surface energy analysis procedures}

In order to analyse the HPDL treated specimens, they were sectioned with a Struers cutting machine using a diamond rimmed cutting blade, and then polished using cloths and diamond suspension pastes down to $3 \mu \mathrm{m}$. The sectioned samples were then examined using optical microscopy, scanning electron microscopy (SEM), energy disperse X-ray analysis (EDX), X-ray diffraction (XRD) techniques and X-ray photoemission spectroscopy (XPS). 
To examine the wetting and surface energy characteristics of the HPDL treated OPC surface two sets of wetting experiments were conducted. The first set of experiments were to simply determine the contact angle between the enamel and the OPC surface before and after HPDL treatment. The second set of experiments were control experiments carried out using a variety of liquids with known surface energy properties in order to quantify any surface energy changes in the OPC surface resulting from HPDL irradiation.

The enamel-HPDL treated OPC surface wetting experiments were carried out in atmospheric conditions with molten droplets of the enamel $\left(600^{\circ} \mathrm{C}\right)$. The temperature of the enamel throughout the experiments was measured using a Cyclops infrared pyrometer. The droplets were released in a controlled manner onto the surface of the OPC surface (treated and untreated) from the tip of a micropipette, with the resultant volume of the drops being approximately $15 \times 10^{-3} \mathrm{~cm}^{3}$. Profile photographs of the sessile enamel drop were obtained for every $60^{\circ} \mathrm{C}$ fall in temperature of the molten enamel drop, with the contact angle subsequently being measured.

The control experiments were carried out using: human blood, human blood plasma, glycerol and 4-octanol. The test liquids, along with their total surface energy $\left(\gamma_{2}\right)$ as well as the dispersive $\left(\gamma_{l v}^{d}\right)$ and polar $\left(\gamma_{l v}^{p}\right)$ components, are detailed in Table 1. The experiments were conducted in atmospheric conditions at a temperature of $20^{\circ} \mathrm{C}$ with the temperature of the liquids themselves throughout the experiments also being maintained at $20^{\circ} \mathrm{C}$. The droplets were released in a controlled manner onto the surface of the test substrate materials (treated and untreated) from the tip of a micropipette, with the resultant volume of the drops being approximately $6 \times 10^{-3} \mathrm{~cm}^{3}$. Each experiment lasted for three minutes with profile photographs of the sessile drops being obtained every minute, with the contact angle subsequently being measured.

\section{Effects of high power diode laser radiation on ordinary Portland cement}

The typical surface morphology of the glaze generated on the OPC surface of concrete when using the HPDL is shown in Fig. 1. As is evident from Fig. 1, crack and porosity formation were common features of the HPDL glaze.

The complex chemistry of the OPC surface of concrete and the hydration of its various constituents are a complex issue. Nonetheless, it is known that the constituents of OPC are minerals which exist 
as multi-component solid solution chemical compounds. Of particular importance with regards this study, OPC contains in relatively large proportions a number of basic glass network formers and modifiers: $\mathrm{SiO}_{2}, \mathrm{Al}_{2} \mathrm{O}_{3}$ and $\mathrm{Fe}_{2} \mathrm{O}_{3}$. Consequently the intense local heating brought about by the incident HPDL beam results in melting of these compounds at around $1283^{\circ} \mathrm{C}$, thereby causing the materials to lose the retained water and form an amorphous glassy material consisting of various calcium-silicate-alumina compounds [4]. Furthermore, the fracture section of the HPDL glaze generated on the OPC surface of concrete is shown in Fig. 2. As one can see from Fig. 2, the microstructure of the HPDL generated glaze has no discernible structure and appears to be fully amorphous. Indeed, the amorphous nature of this glaze was verified by XRD analysis results shown in Fig. 3.

In addition, distinct changes in the colour of the OPC surface were observed after HPDL treatment. Typically the OPC surface changed colour from grey to green. These changes are due to the resultant phase transitions and also, the presence in small concentrations of metal transition ions in various oxidation states within the $\mathrm{OPC}$ composition, in particular, ferric ions in the $\mathrm{Fe}^{3+}$ and $\mathrm{Fe}^{2+}$ oxidation state. $\mathrm{Fe}^{3+}$ and $\mathrm{Fe}^{2+}$ ions are known to give rise to green and blue colours respectively when subjected to intense heating $[37,38]$. However, if both phases are present within the composition, then the colour is determined by the $\mathrm{Fe}^{3+} / \mathrm{Fe}^{2+}$ ion ratio, resulting in dark blue or black colours $[37,38]$. Since the surface produced after HPDL treatment was green, then it is reasonable to assume that both phases were not present within the OPC.

Petzold et al. [39] have determined from differential thermal analysis (DTA) results that up to approximately $420^{\circ} \mathrm{C}$, OPC remains relatively stable. Notwithstanding this, some dehydration does occur and water is also lost from the pores of the cement. This is, however, far outweighed by the dehydration of $\mathrm{Ca}(\mathrm{OH})_{2}$ which follows shortly after $420^{\circ} \mathrm{C}$ is exceeded in accordance with

$$
\mathrm{Ca}(\mathrm{OH})_{2} \rightarrow \mathrm{CaO}+\mathrm{H}_{2} \mathrm{O}
$$

Furthermore, the dehydration of the $\mathrm{Ca}(\mathrm{OH})_{2}$ promotes the development of microcracks which begin initially around the $\mathrm{Ca}(\mathrm{OH})_{2}[40]$. Moreover, this dehydration results in unslaked lime $(\mathrm{CaO})$, which is effectively the generated HAZ; since the temperature of the surface of the OPC during interaction with the HPDL during glazing was measured to be well in excess of $420^{\circ} \mathrm{C}$. This generated $\mathrm{CaO} \mathrm{HAZ}$ was observed located either below the glazed surface layer or around the edges of the glazes. Indeed, by using a phenolphthalein indicator followed by water misting, it was possible to clearly discern the 
HAZ around the HPDL treated zone on the OPC surface of the concrete, since phenolphthalein is an indicator which is colourless in $\mathrm{CaO}$, turning violet-red in the presence of $\mathrm{Ca}(\mathrm{OH})_{2}$ due to the change in $\mathrm{pH}$.

\section{High power diode laser fired enamel glaze characteristics}

It was observed that, prior to HPDL irradiation, it was not possible to fire the enamel onto the OPC surface of concrete. Indeed, HPDL interaction with the enamel when placed on the untreated OPC surface simply resulted in the 'balling' of the enamel (the formation of small spheres approximately the diameter of the laser beam itself). Such observations are in accord with those of Bourell et al. [41] and Agarwala et al. [42], who noted the balling phenomena during laser sintering work of silica based materials. After HPDL surface treatment of the OPC surface, however, it was possible to fire the enamel directly onto the OPC surface. The mechanism of this phenomena is based entirely on the wettability characteristics of the OPC surface.

The typical surface morphology of the HPDL fired enamel glaze produced on the HPDL treated OPC surface of concrete is shown in Fig. 4. As can be seen from Fig. 4, neither crack nor porosity formation were discernible on the enamel glaze. An XRD analysis of the HPDL fired enamel glaze revealed it to be fully amorphous.

The typical cross-sectional view of the HPDL fired enamel glaze produced on the HPDL treated OPC surface of concrete is shown in Fig. 5. As one can see from Fig. 5, the enamel glaze appears to be well bonded to the HPDL treated OPC surface of concrete.

\section{Wettability and surface energy characteristics}

\subsection{Contact angle and wettability}

As was mentioned earlier, it proved impossible to fire the enamel glaze directly onto the OPC surface without prior HPDL treatment. An optical micrograph of a sessile drop of enamel $\left(20^{\circ} \mathrm{C}\right)$ placed on the surface of the OPC before (a) and after (b) HPDL irradiation with the contact angle superimposed is shown in Fig. 6. The experimental results showed that throughout the period of cooling of the enamel, from the molten state at $600^{\circ} \mathrm{C}$ to the solid state at room temperature, no discernible change in the magnitude of the of the contact angle took place during the time of the experiments. This 
indicates that thermodynamic equilibrium was established at the solid-liquid interface at the outset of the experiment [43]. Fig. 6 shows clearly that prior to HPDL treatment it was not possible to fire the enamel onto the surface of the OPC since the contact angle was measured as $109^{\circ}$, and as such would prevent the enamel from wetting the OPC surface.

One explanation for the fact that HPDL treatment of the OPC is necessary so that the enamel completely wets and adheres to the surface is that the surface resulting from the HPDL treatment is somewhat smoother, with an Ra value of $2.88 \mu \mathrm{m}$ compared with $21.91 \mu \mathrm{m}$, and, according to Eq. (4), will intrinsically effect a reduction in the contact angle. Also, wetting will have certainly been influenced by the increase in the $\mathrm{O}_{2}$ content of the OPC surface as a result of the HPDL treatment, since this is known to increase the likelihood of wetting $[43,44]$. Wetting is governed by the first atomic layers of the surface of a material. Thus, in order to determine element content of $\mathrm{O}_{2}$ at the surface of the OPC, it was necessary to examine the surface using XPS analysis. A difference in the surface $\mathrm{O}_{2}$ content of the OPC before and after HPDL treatment was observed, increasing from an initial value of 44.7 at. $\%$ to 49.2 at $\%$.

\subsection{Ordinary Portland cement surface energy and its dispersive/polar character}

In accordance with studies conducted by Fowkes [36] and Agathopoulos [43], it is possible to estimate reasonably accurately the dispersive component of the OPC surface energy, $\gamma_{s v}^{d}$, by plotting the graph of $\cos \theta$ against $\left(\gamma_{l v}^{d}\right)^{1 / 2} / \gamma_{1 v}$ in accordance with Eq. (7) [36], with the value of $\gamma_{s v}^{d}$ being estimated by the gradient $\left(=2\left(\gamma_{s v}^{d}\right)^{1 / 2}\right)$ of the line which connects the origin $(\cos \theta=-1)$ with the intercept point of the straight line $\left(\cos \theta\right.$ against $\left.\left(\gamma_{l v}^{d}\right)^{1 / 2} / \gamma_{\mathrm{lv}}\right)$ correlating the data point with the abscissa at $\cos \theta=1$. Fig. 7 shows the best-fit plot of $\cos \theta$ against $\left(\gamma_{l v}^{d}\right)^{1 / 2} / \gamma_{\mathrm{lv}}$ for the untreated and HPDL treated OPC-experimental control liquids system.

Comparing the ordinate intercept points of the untreated and HPDL treated OPC-liquid systems, it can be seen clearly from Fig. 7 that for the untreated OPC-liquid systems the best-fit straight line intercepts the ordinate closer to the origin. This indicates that, in principle, dispersion forces act mainly at the OPC-liquid interfaces resulting in poor adhesion [36, 47]. In contrast, Fig. 7 shows that the best-fit straight line for the HPDL treated OPC-liquid systems intercepts the ordinate considerably higher above the origin. This is indicative of the action of polar forces across the interface, in addition to dispersion forces, hence improved wettability and adhesion is promoted [36, 46]. 
Again, in accordance with studies conducted by Fowkes [36] and Agathopoulos et al. [43], it is not possible to determine the value of the polar component of the OPC's surface energy $\gamma_{s v}^{p}$ directly from Fig. 7. This is because the intercept of the straight line $\left(\cos \theta\right.$ against $\left.\left(\gamma_{l v}^{d}\right)^{1 / 2} / \gamma_{\mathrm{lv}}\right)$ is at $2\left(\gamma_{s v}^{p} \gamma_{l v}^{p}\right)^{1 / 2} / \gamma_{\mathrm{lv}}$, and thus only refers to individual control liquids and not the control liquid system. However, it has been established that the entire amount of the surface energies due to dispersion forces either of the solids or the liquids are active in the wettability performance [36, 47]. Thus it is possible to calculate the dispersive component of the work of adhesion, $W_{a d}^{d}$ from Eq. (6). The results reveal that for each particular control liquid in contact with both the untreated and HPDL treated OPC surfaces, $W_{a d}$ can be correlated with $W_{a d}^{d}$ by the relationship

$$
W_{a d}=a W_{a d}^{d}+b
$$

where $a$ and $b$ are constants unique to each control liquid system. Also, for the control test liquids used, a linear relationship between the dispersive and polar components of the control test liquids surface energies has been deduced which satisfies the equation

$$
\left(\gamma_{l v}^{p}\right)^{1 / 2}=1.3\left(\gamma_{l v}^{d}\right)^{1 / 2}+1.15
$$

By introducing Eq. (9) into Eq. (6) and rearranging, then

$$
W_{a d}^{p}=(a-1) W_{a d}^{d}+b
$$

By introducing Eq. (10) into Eq. (11) and differentiating with respect to $\left(\gamma_{v}^{d}\right)^{1 / 2}$, then the following can be derived:

$$
\left(\gamma_{s v}^{p}\right)^{1 / 2}=\frac{\left(\gamma_{s v}^{d}\right)^{1 / 2}(a-1)}{1.3}
$$

From a plot of Eq. (9), $a$ can be determined for the untreated and HPDL treated OPC (1.3 and 1.6 respectively). Since $\gamma_{s v}^{d}$ has already been determined for the untreated and HPDL treated OPC from Fig. 7, then it is possible to calculate $\gamma_{s v}^{p}$ for untreated and HPDL treated OPC using Eq. (12). 
Table 2 details the values determined for $\gamma_{s v}^{d}$ and $\gamma_{s v}^{p}$ for both the untreated and HPDL treated OPC. Clearly the HPDL treatment of the surface of the OPC leads to a reduction in the total surface energy $\gamma_{s v}$, whilst increasing the polar component of the surface energy $\gamma_{s v}^{p}$, thus improving the action of wetting and adhesion. Such changes in the surface energy of the OPC after HPDL treatment are due to the fact that HPDL treatment of the surface of the OPC results in partial vitrification of the surface; a transition that is known to effect a reduction in $\gamma_{\mathrm{sv}}$ and an increase in $\gamma_{s v}^{p}$ [43].

It is important to note that because of the long range ionic interactions in the OPC and the composite nature of the interfaces between the OPC and the liquids, it is highly likely that the thermodynamically defined total solid surface energy, $\gamma$, as defined in Eq. (5), will be higher than the sum of the dispersive, $\gamma^{\mathrm{d}}$, and the polar, $\gamma^{\mathrm{p}}$, components of the surface energy. Although the increase in (excess) surface free energy will probably be less then the increase in the total lattice energy. On the other hand an absorbed liquid layer may shield the ionic fields substantially. As such, all the data derived from Eq. (6) - (7) and Eq. (9) - (12) should be considered as being semi-empirical. Nevertheless, as the studies by Gutowski et al. [48] and Agathopoulos et al. [43] found, it is reasonable to conclude from the data obtained from Eq. (6) - (7) and Eq. (9) - (12) that HPDL treatment of the OPC surface has effected an increase in $\gamma^{\mathrm{p}}$.

\section{Conclusions}

Contact angle measurements revealed that, because of the wettability characteristics of the OPC, HPDL surface treatment was necessary in order to allow the enamel to wet and adhere to the OPC surface. As such, the HPDL treatment of the OPC surface resulted in the contact angle decreasing from $109^{\circ}$ to $31^{0}$. Wetting, and the subsequent bonding, of the enamel to the OPC surface after HPDL treatment was identified as being due to:

1. The HPDL vitrification of the OPC surface reducing the surface roughness from an Ra value of $21.91 \mu \mathrm{m}$ before HPDL treatment, to $2.88 \mu \mathrm{m}$ after HPDL treatment, thus directly reducing the contact angle $\theta$.

2. The increase in the polar component of the surface energy, $\gamma_{s v}^{p},\left(3.46 \mathrm{mJm}^{-2}\right.$ to $\left.15.56 \mathrm{mJm}^{-2}\right)$ after HPDL treatment as a result of the laser vitrification of the glass forming elements within the OPC composition, thus improving the action of wetting and adhesion. 
3. The increase in the surface $\mathrm{O}_{2}$ content of the OPC from 44.7 at $\%$ to 49.2 at $\%$ resulting from HPDL treatment was identified as further promoting the action of wetting.

This work demonstrates that it is possible to alter the wetting characteristics of the OPC using the HPDL to facilitate the firing of a vitreous enamel onto the OPC surface, an achievement not possible without HPDL treatment. But, moreover, the findings of this work show that with the use of laser radiation it is a distinct possibility that the wetting characteristics of many other materials could be altered. 


\section{References}

1. J. Lawrence and L. Li, J. Mater. Process. Tech. (submitted).

2. K. Sugita, M. Mori, T. Fujioka, Concrete Eng. 24 (1986) 13.

3. M. Hamasaki, Proc. of The International Symposium on Laser Processing, Boston, USA, 1987, 158.

4. H. Yoshizawa, S. Wignarajah, H. Saito, Trans. Japan Welding Soc. 20 (1989) 31.

5. L. Li, P.J. Modern, W.M. Steen, Proc. of LAMP '92, Osaka, Japan 1992, 843.

6. L. Li, W.M. Steen, P.J. Modern, Proc. of ISLOE '93, Singapore, 1994, 25.

7. L. Li, W.M. Steen, P.J. Modern, J.T. Spencer, Proc. of RECOD '94, London, UK, 1994, 24.

8. L. Li, W.M. Steen, P.J. Modern, J.T. Spencer, Proc. of EUROPTO '94: Laser Materials Processing and Machining, Munich, Germany, 1994, 84.

9. K. Sugimoto, S. Wignarajah, K. Nagasi, S. Yasu, Proc. of ICALEO '90: Laser Materials Processing, Boston, USA, 1990, 302.

10. S. Wignarajah, K. Sugimoto, K. Nagai, Proc. of ICALEO '92: Laser Materials Processing, Orlando, USA, 1992, 383.

11. T.I. Borodina, G.E. Valyano, N.I. Ibragimov, E.P. Pakhomov, A.I. Romanov, L.G. Smirnova, P.K. Khabibulaev, J. Phys. and Chem. of Mater. Treatment, 25 (1995) 541.

12. J. Lawrence and L. Li, Proc. of ICALEO '99: Laser Materials Processing, Orlando, USA, 1999, 334.

13. J. Lawrence, L. Li, Mater. Sci. Eng. A, 284 (2000) 93.

14. J. Lawrence, L. Li, Mater. Sci. Eng. A, 287 (2000) 25.

15. J. Lawrence, L. Li, J. Laser Apps. 72 (2000) 8.

16. X.B. Zhou and J.Th.M. de Hosson, J. de Physique IV, 3 (1993) 1007.

17. X.B. Zhou and J.Th.M. de Hosson, Acta Metallurgica et Materialia, 42 (1994) 1155.

18. J. Heitz, E. Arenholz, T. Kefer, D. Bäuerle, H. Hibst and A. Hagemeyer, Appl. Phys. A, 55 (1992) 391 . 
19. F. Henari and W. Blau, Appl. Optics 34 (1995) 581.

20. M. Olfert, W. Duley and T. North, in: J. Mazumder (Ed.), Laser Processing, Kluwer Academic Publishing, Amsterdam 1996, pp. 479-490.

21. J. Lawrence and L. Li, J. Phys. D, 32 (1999) 2311.

22. J. Lawrence and L. Li, Appl. Surf. Sci. 154/155 (2000) 664.

23. J. Lawrence and L. Li, J. Phys. D, 32 (1999) 1075.

24. J. Lawrence, L. Li and J.T. Spencer, Proc. of ICALEO’96: Laser Materials Processing, Detroit, USA, 1996, 138.

25. J. Lawrence, L. Li and J.T. Spencer, Optics and Laser Tech. 30 (1998) 205.

26. J. Lawrence, L. Li and J.T. Spencer, Optics and Laser Tech. 30 (1998) 215.

27. J. Lawrence, PhD Thesis, University of Manchester Institute of Science \& Technology (UMIST), 1999.

28. J. Lawrence and L. Li, J. Mater. Process. Tech. (submitted).

29. J. Lawrence and L. Li, J. Eng. Manuf., Proc. IMechE, (accepted).

30. M.J. Jaycock and G.D. Parfitt, Chemistry of Interfaces, John Wiley \& Sons, Chichester, 1981, pp. 234-247.

31. W.A. Zisman, in: R.F. Gould (Ed.), Advances in Adhesion Chemistry Series 43: Contact Angle, Wettability and Adhesion, American Chemical Society, Washington DC, 1964, pp. 1-51.

32. R.N Wenzel, Ind. Eng. Chem. 28 (1936) 988.

33. A.B.D. Cassie, S. Baxter, Trans. Faraday Soc. 40 (1944) 546.

34. X.B. Zhou, J.Th.M. De Hosson, J. Mat. Research 10 (1995) 1984.

35. A.W. Neumann, Adv. Colloid Interface Sci. 4 (1974) 438.

36. F.M. Fowkes, Ind. Eng. Chem. 56 (1964) 40.

37. G.D. Taylor, Construction Materials, Longman Scientific \& Technical, London, 1991, pp. 31-34.

38. N. Jackson and R.K. Dhir, Civil Engineering Materials, MacMillan Press, New York, 1992, pp. 90-92. 
39. A. Petzold and M. Rohrs, Concrete for High Temperatures, MacLaren \& Sons, London, 1970, pp. 40-85.

40. Schneider and U. Diederichs, Betonwerk \& Fertigteil - Technik 3 (1981) 141.

41. D.L. Bourell, H.L. Marcus, J.W. Barlow and J.J. Beaman, Int. J. Powder Metallurgy, 28 (1992) 369.

42. M. Agarwala, D.L. Bourell, J.J. Beaman, H.L. Marcus and J.W. Barlow, Rapid Prototyping J., 1 (1995) 26.

43. S. Agathopoulos and P. Nikolopoulos, J. of Biomed. Mater. Res. 29 (1995) 421.

44. M. Ueki, M. Naka and I. Okamoto, J. Mater. Sci. Lett. 5 (1986) 1261.

45. J.G. Li, Rare Met. 2 (1993) 84-96.

46. D.K. Chattoraj and K.S. Birdi, Adsorption and the Gibbs Surface Excess, Plenum Press, New York, 1984 p. 95.

47. R.J. Good and L.A. Girifalco, J. Phys. Chem. 64 (1960) 561.

48. V.W. Gutowski, L. Russell, A. Cerra, in: J.M. Klosowski (Ed.), Science and Technology of Building Seals, Sealants, Glazing and Waterproofing, ASTM, Philadelphia, 1992, pp. 144-159. 


\section{LIST OF FIGS.}

Fig. 1. Typical optical surface morphology of the HPDL generated OPC surface glaze. $\left(2.25 \mathrm{~kW} / \mathrm{cm}^{2}\right.$ power density, $240 \mathrm{~mm} / \mathrm{min}$ traverse speed)

Fig. 2. Typical SEM micrograph of the fracture section of the HPDL generated OPC surface glaze. $\left(2.25 \mathrm{~kW} / \mathrm{cm}^{2}\right.$ power density, $240 \mathrm{~mm} / \mathrm{min}$ traverse speed)

Fig. 3. XRD analysis of the HPDL treated OPC surface.

Fig. 4. Typical optical surface morphology of the HPDL fired enamel glaze on HPDL treated OPC. $\left(1.75 \mathrm{~kW} / \mathrm{cm}^{2}\right.$ power density, $360 \mathrm{~mm} / \mathrm{min}^{1}$ traverse speed)

Fig. 5. Typical SEM micrograph of the cross-section of the HPDL fired enamel glaze on HPDL treated OPC. (1.75 kW/ $\mathrm{cm}^{2}$ power density, $360 \mathrm{~mm} / \mathrm{min}$ traverse speed)

Fig. 6. Contact angles for the enamel on (a) the untreated surface of the OPC and (b) the HPDL treated surface of the OPC.

Fig. 7. Plot of $\cos \theta$ against $\left(\gamma_{l v}^{d}\right)^{1 / 2} / \gamma_{v}$ for the untreated and HPDL treated OPC in contact with the wetting test control liquids. 
Fig. 1.

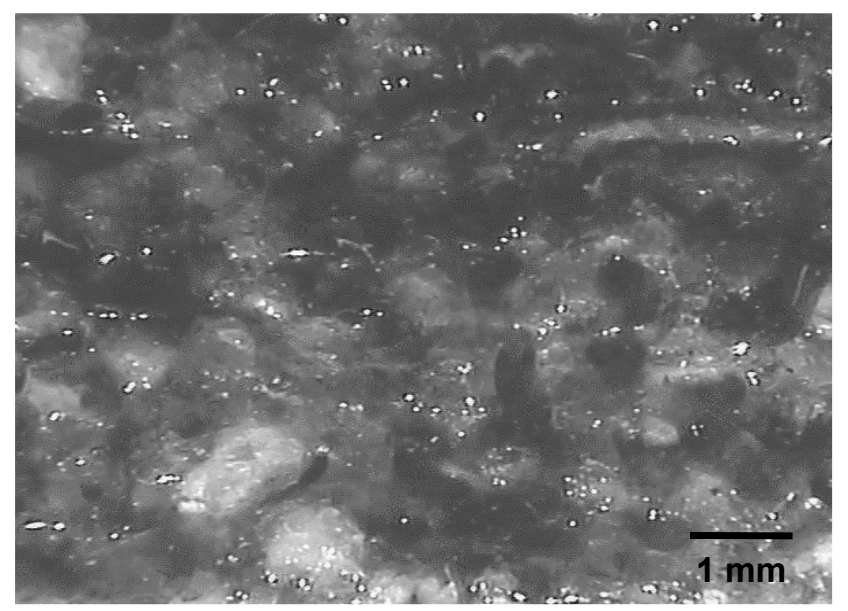

Fig. 2. 


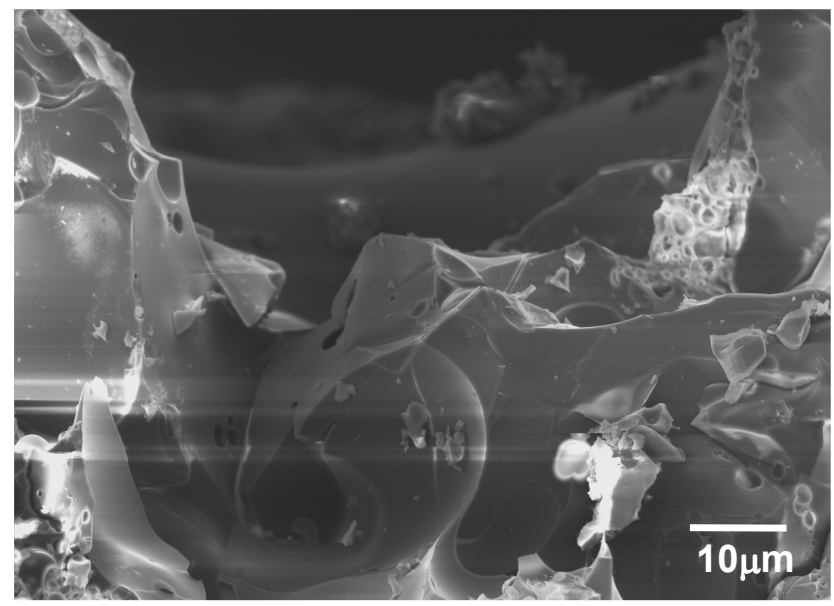


Fig. 3.

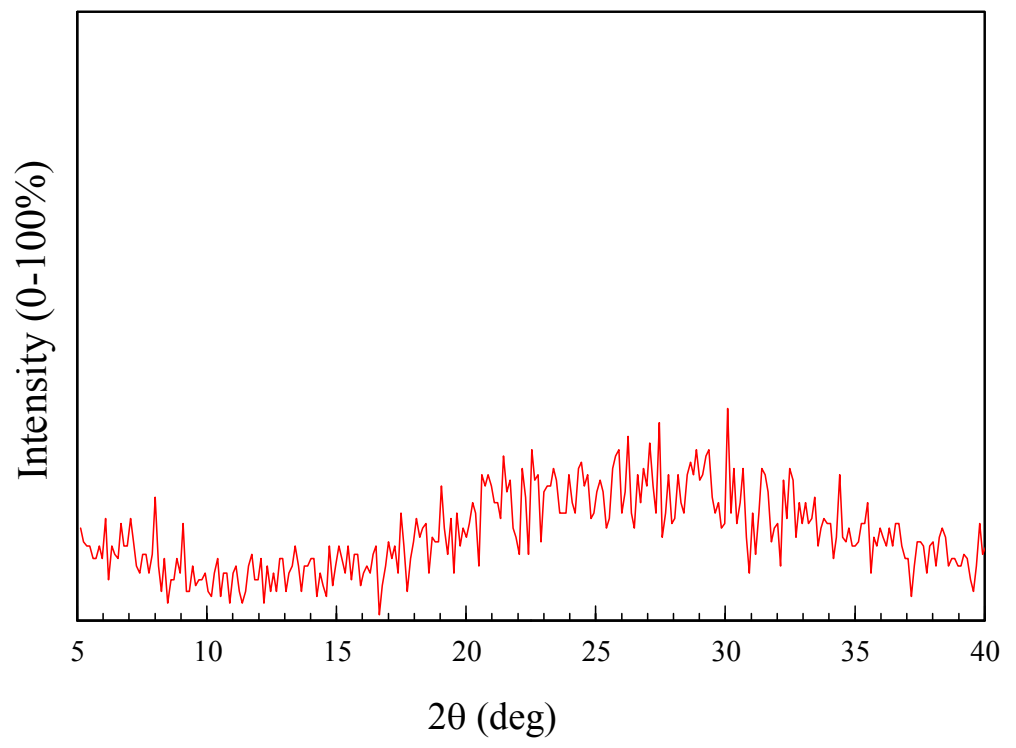


Fig. 4.

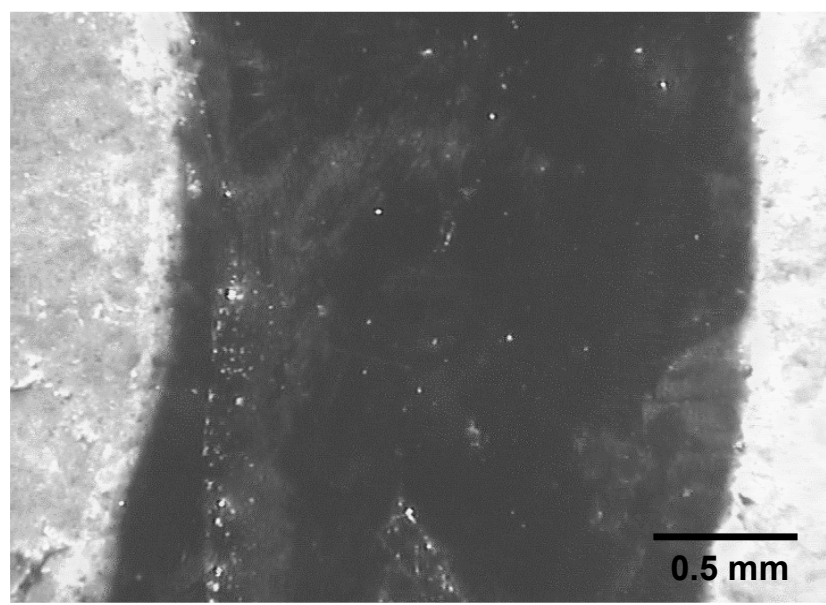


Fig. 5.

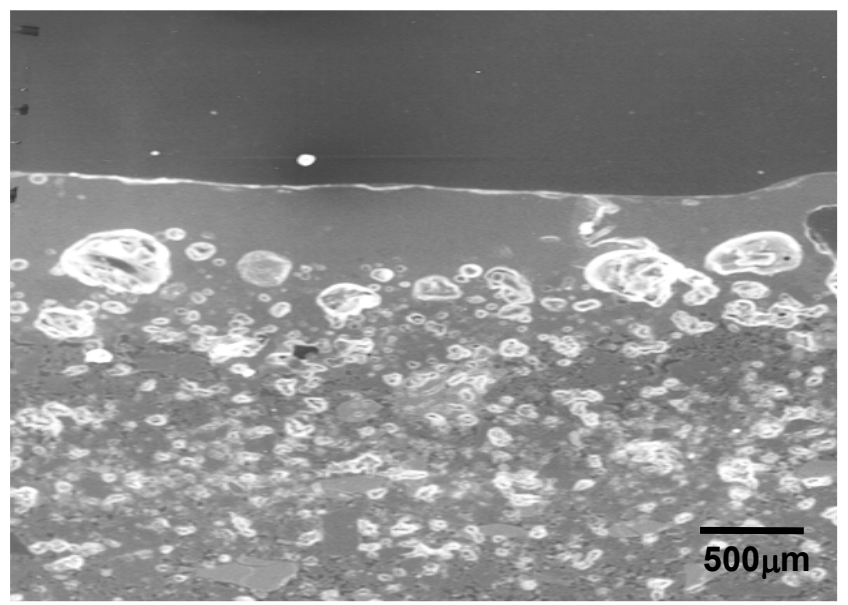


Fig. 6.

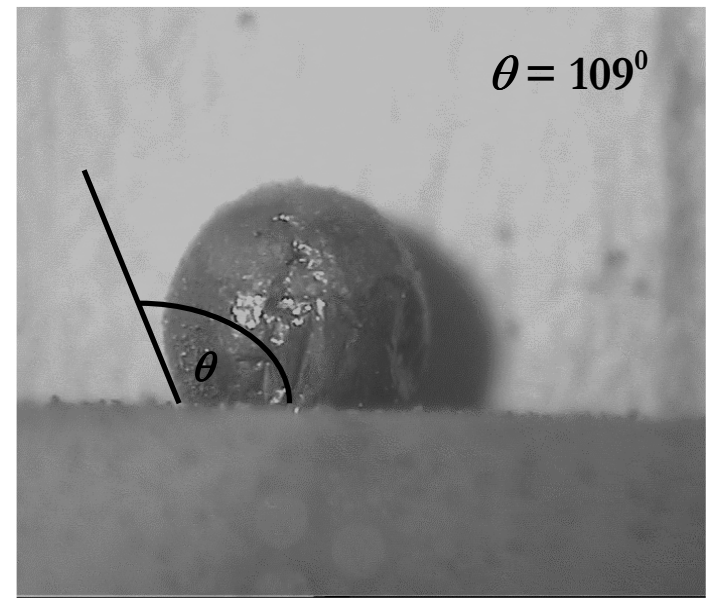

(a)

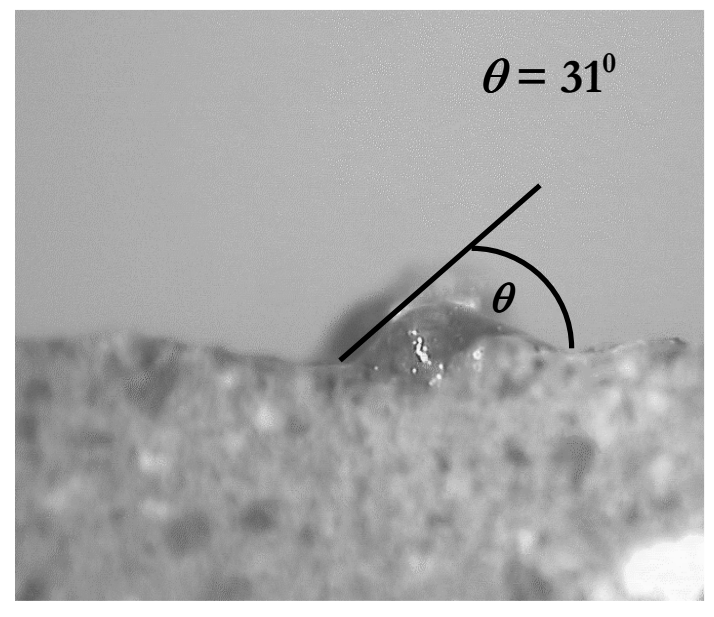

(b) 
Fig. 7.

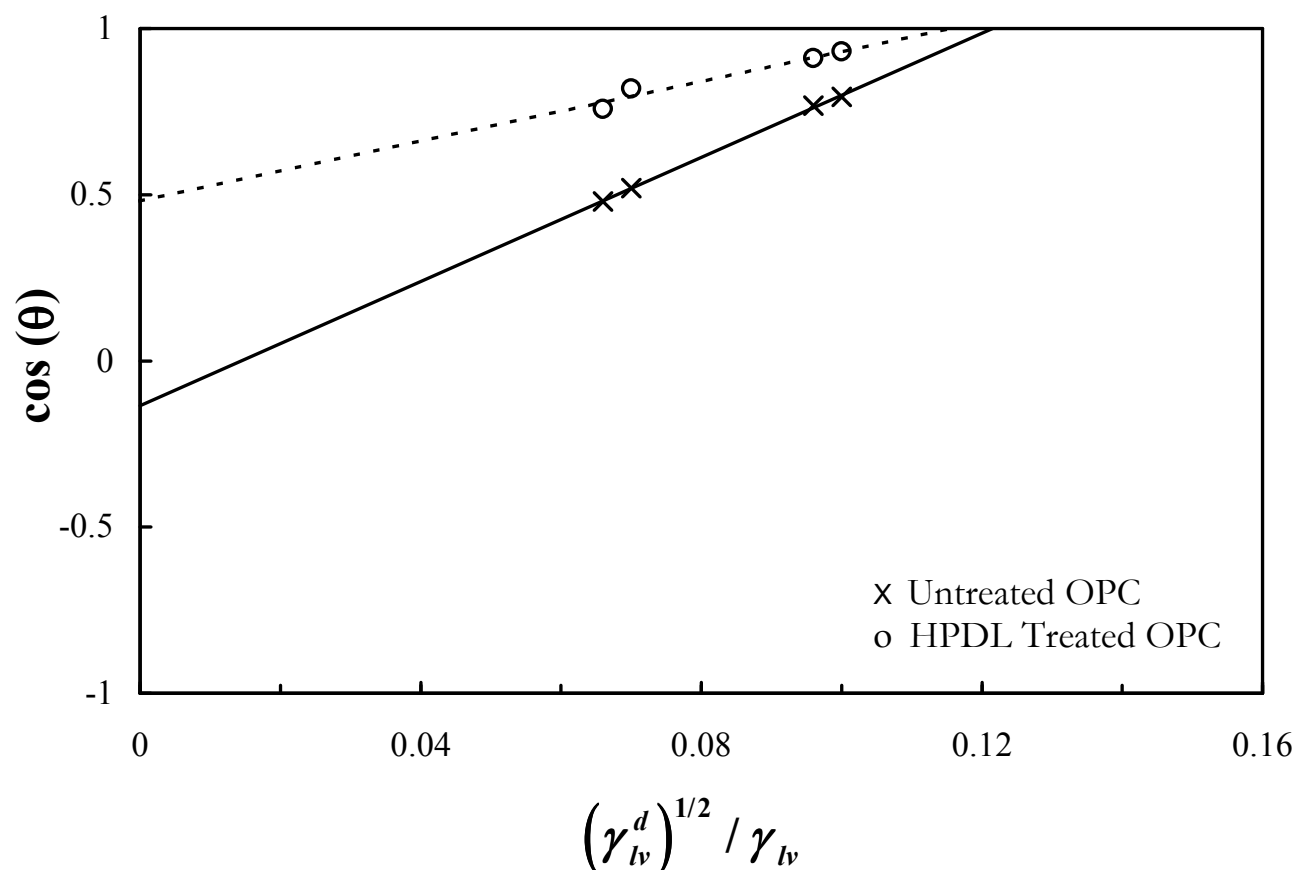




\section{LIST OF TABLES}

Table 1. Total surface energy $\left(\gamma_{\mathrm{lv}}\right)$ and the dispersive $\left(\gamma_{l v}^{d}\right)$ and polar $\left(\gamma_{l v}^{p}\right)$ components for the selected test liquids [12].

Table 2. Measured surface energy values for the OPC before and after HPDL irradiation. 
$\underline{\text { Table } 1}$

\begin{tabular}{lccc}
\hline Liquid & $\begin{array}{c}\gamma \\
(\mathbf{m J m}\end{array}$ & $\begin{array}{c}\gamma_{l v}^{d} \\
\left(\mathbf{m J m}^{-2}\right)\end{array}$ & $\begin{array}{c}\gamma_{l v}^{p} \\
\left(\mathbf{m J m}^{-2}\right)\end{array}$ \\
\hline Human Blood & 47.5 & 11.2 & 36.3 \\
Human Blood Plasma & 50.5 & 11.0 & 39.5 \\
Glycerol & 63.4 & 37.0 & 26.4 \\
4-Octonol & 27.5 & 7.4 & 20.1 \\
\hline
\end{tabular}


$\underline{\text { Table } 2}$

\begin{tabular}{lcc}
\hline Surface Energy Component & Untreated OPC & HPDL Treated OPC \\
\hline Dispersive Component, $\left(\gamma_{s v}^{d}\right)$ & $65.03 \mathrm{mJm}^{-2}$ & $73.05 \mathrm{mJm}^{-2}$ \\
Polar Component, $\left(\gamma_{s v}^{p}\right)$ & $3.46 \mathrm{mJm}^{-2}$ & $15.56 \mathrm{mJm}^{-2}$ \\
\hline
\end{tabular}

